\title{
A Hybrid Methodology Based on Smart Management Energy Consumption in Irrigation Systems
}

\author{
Florina Scarlatache * $\mathbb{D}$, Gheorghe Grigoras $(\mathbb{D}$, Vlad-Andrei Scarlatache, Bogdan-Constantin Neagu $\mathbb{D}$ \\ and Ovidiu Ivanov
}

check for updates

Citation: Scarlatache, F.; Grigoras, G.; Scarlatache, V.-A.; Neagu, B.-C.; Ivanov, O. A Hybrid Methodology Based on Smart Management Energy Consumption in Irrigation Systems. Electronics 2021, 10, 2864. https:// doi.org/10.3390/electronics10222864

Academic Editor: Yi-Hua Liu

Received: 18 October 2021

Accepted: 19 November 2021

Published: 20 November 2021

Publisher's Note: MDPI stays neutral with regard to jurisdictional claims in published maps and institutional affiliations.

Copyright: (c) 2021 by the authors. Licensee MDPI, Basel, Switzerland. This article is an open access article distributed under the terms and conditions of the Creative Commons Attribution (CC BY) license (https:// creativecommons.org/licenses/by/ $4.0 /)$.
Department of Power Engineering, “Gheorghe Asachi” Technical University of Iasi, 700050 Iasi, Romania; ggrigor@tuiasi.ro (G.G.); vlad-andrei.scarlatache@academic.tuiasi.ro (V.-A.S.); bogdan.neagu@tuiasi.ro (B.-C.N.); ovidiuivanov@tuiasi.ro (O.I.)

* Correspondence: florina.scarlatache@academic.tuiasi.ro

\begin{abstract}
Innovative practices in irrigation systems can bring improvements in terms of economic efficiency and, at the same time, can reduce environmental impacts. Investment in high-tech technologies frequently involves additional costs, but an efficient water management system can increase the lifetime of the equipment. The most utilized electronic device for a smart management, used to pump units from irrigation systems, is the frequency converter. This device can regulate the speed of the motors that control the pumps according to the consumption of water, ensuring that it does not pump more water than is needed. This paper develops a new operating algorithm that ensures the operation of the pumping group at safe operating intervals and identifies the equivalent pump operating points for the entire flow range and pumping height of the pumping group in order to bring smart management to irrigation systems. The parameters monitored and collected for each vertical pump refers to the voltage, current, frequency (speeds) and flow of each hydraulic operating mode. The methodology used is based on the principle of creating an expert system to optimize energy consumption in the pumping groups. The proposed methodology was tested on an irrigation system that includes a pumping group with five pumps, showing its effectiveness in obtaining the optimal solution with a relatively low computational burden and without the violation of any system constraints under any operating conditions.
\end{abstract}

Keywords: energy saving; optimization; expert system; smart irrigation system

\section{Introduction}

The irrigation systems in crops contain odd-looking metal pipe structures on wheels that stretch across the fields. These metal monsters, known as pivot irrigation systems, are widely used in agriculture and have considerably improved the efficiency of the irrigation process. These irrigation systems were designed to take a large amount of manual work out of irrigation and make it easier on the farmer to control the irrigation process in multiple locations. Over the years, irrigation systems have gone through various improvements and today, many options are available including water, hydraulic and electrically driven versions, [1].

Nowadays, modern irrigation systems are equipped with PLCs (programmable logic controllers) in the control panel for a better status monitoring process (purchasing the device inputs via sensors, buttons, state variables of the process) and an automated control (which involves processing the input information and generating the required commands to automation process, according to a specific program). The most utilized electronic device for smart management, pumping units from irrigation systems, is the frequency converter. This device can regulate the speed of the motors that control the pumps according to the consumption of water, thereby ensuring it does not pump more water than is needed. New control technologies in irrigation systems could enhance the irrigation efficiency, stimulating water conservation and reducing the environmental impact $[2,3]$. 
The necessity for a more integrated and sustainable approach to control water resources in Europe is reflected in water-related policy and legislation. In recent decades, the European Union has implemented a wide range of environmental legislation. As a consequence, water, air and soil pollution have been meaningfully attenuated. Nowadays, EU citizens enjoy some of the best water quality in the world and more than $18 \%$ of EU territory has been elevated to a protected area status [4,5]. However, many challenges persist, and these must be approached together in a structured way. These challenges are the reason for promoting integrated water resource management, a process that involves all stakeholders, from policy makers to water suppliers and end-users. Currently, the 8th Environment Action Program (EAP) guides the European environment policy until 2030 [6]. One of the most important objectives of this program is to manage water resources in a sustainable and integrated way, accelerating the transition to a climate-neutral, resourceefficient and regenerative economy, in a way that gives back more than it takes from the planet. The national, regional and local authorities need to introduce measures to improve this efficiency and to encourage the necessary changes in agricultural practices to protect water resources and to increase the environmental quality.

For optimal irrigation management, it is always important, as far as possible, to have automatic irrigation control systems. Many advantages can be attributed to an efficient irrigation control system, such as saving energy, labor and water, as well as increasing the efficiency of irrigation, reducing maintenance costs and raising production outputs due to the optimization of irrigation $[7,8]$. In this paper, we attempt to maximize these advantages through the use of an integrated control system that can be embedded in a programmable controller, transmitting the control signal to the frequency converter. The integrated control system identifies the maximum efficiency point and the minimum energy consumption in the entire irrigation system using a decision matrix which takes into account the pumping cost, the pumping group efficiency and the total flow required at a constant pressure. This is in contrast to previous studies that consider soil moisture, [9], air temperature and solar radiation, [10] irrigation water withdrawal in [11] and pump speed and flow in [12].

In the literature, various studies have been carried out regarding optimal irrigation management, with each researcher having a different point of view on this subject. Most of the proposed works focus on the design of a controller that can support the levels required in the irrigation canals, thereby satisfying the water irrigation demand. However, the most important problem encountered in practice addresses: how to serve the water demand in order to reduce the energy consumption by optimally scheduling the pumping groups.

Table 1 present a synthesis of the solutions proposed in literature depending on the type of analysis (efficient use of irrigation water or the reduction of energy consumption) and the type of optimization method (classical or artificial intelligence). Most of the papers formulated the analysis neglecting the importance of energy consumption in the process of controlling water resources. Classical optimization methods, based on linear programming models, were used to optimize water use in [13] and to allocate available land and water resources in order to maximize net annual returns by mitigating the waterlogging problem in [14]. Nonlinear programming was used for determining optimum crop patterns under deficit irrigation conditions with regards to regional limitations and water availability in [15]. Nonlinear programming was also used to estimate the direct and indirect energy consumption of field operations in a lowland rice production system in order to indicate the energy gain [16]. Quadratic programming was used to maximize the net benefit of an optimization model for crop irrigation scheduling under uncertain conditions in [17], ensuring the optimal management of water and energy as part of the Bardenas irrigation system in [18]. Dynamic programming was used to determine the crop yield response to water deficits in [19] and was also developed for the irrigation management of greenhouse crops for an economic impact evaluation in irrigation systems [20]. Artificial intelligence techniques (AI) are able to solve the problems of irrigation systems which are non-linear, complex and ill-defined. Thus, genetic algorithms can optimize the economic benefit, simulate the water demand and search the related crop area percentages with a specified 
water supply [21]. This can also minimize energy costs in [22] and determine the smallest annual cost of pumping stations, satisfying target hydraulic performance requirements in paper [23]. Fuzzy techniques were used to model soil moisture content deviation and the rate of change of deviation as input variables of a fuzzy controller. The fuzzy control regular database was established for the fuzzy irrigation control system in [24]. A hybrid system, based on generating appropriate notifications using a fuzzy logic-based weather model, was utilized to solve the problem of generating the best irrigation suggestions for farmers, as proposed in [25]. In [26], a fuzzy decision support method has been presented to monitor some of the parameters in an irrigation system: air moisture and temperature, soil air and moisture and evapotranspiration in order to optimize the efficiency of irrigation systems. In [27], a neural network was used to design an automatic irrigation neuro-controller for precision agriculture in order to regulates the level of moisture in agricultural soils. Expert systems were used in [28] to make decisions regarding water management in an irrigation system. Optimal water use was discussed in [29] and precision irrigation management was addressed in [30]. These artificial intelligence algorithms were designed to emulate the human decision-making process and were deployed for the implementation of adaptive decision support in the irrigation process.

Table 1. Synthesis of the literature approaches.

\begin{tabular}{cccc}
\hline & & \multicolumn{2}{c}{ Methods } \\
\hline & Classical & Artificial Intelligence \\
\hline \multirow{2}{*}{ Type of study } & Energy consumption & {$[13-15,17,19,20]$} & {$[21,24,25,27-30]$} \\
& Ener & {$[16,18]$} & {$[22,23,26]$} \\
\hline
\end{tabular}

Using new technologies based on innovative tools, the farmers can cope with the challenges and requirements of the future. By making the best available operational decisions, the efficiency will increase and the revenue will rise. Optimal irrigation control implies good coordination between each pump from the pumping groups.

This paper proposes a hybrid methodology that can control the pumping groups within an irrigation system. The main objective of this paper is to reduce energy consumption for every 1000 cubic meters pumped and to automatically increase the economic efficiency of the pumping groups.

This paper aims to develop an integrated system, based on expert system principles, that, in addition to ensuring the operation of the pumping group at safe operating intervals, identifies the equivalent pump operating points for the entire flow range and pumping height of the pumping group. Thus, indifferent of the pumping heights and flow ranges at a given time, the maximum efficiency point can be identified and managed to achieve the minimum energy consumption.

The main contributions of the paper are:

- An original method for optimal irrigation management to reduce energy consumption at for every 1000 cubic meters pumped;

- The adaptation of an integrated system for power consumption optimization in pumping groups to exploit the knowledge on the irrigation system operational characteristics;

- The validation of a proposed methodology presented in a case study that uses real input data from Romanian irrigation systems.

Considering these aspects, the research, techniques, methods and procedures for the command and control of the pumping groups were developed within an expert system (ES). This was completed in order to achieve the objective function, to minimize the energy consumption at a thousand cubic meters pumped, and take into account a number of constraints, such as maintaining constant pressure, the cost of pumping as low as possible and the highest efficiency of the equivalent pump. This methodology aims to determine the maximum efficiency point of an irrigation system in different hydraulic regimes. This 
maximum efficiency point represents the optimal frequency band for which the pumping cost is minimal.

The remainder of this paper is organized as follows: Section 2 describes the principles of an expert system, synthesizing the existing approaches and providing the rationale for developing the proposed methodology for the optimization process of energy consumption in pumping groups; Section 3 presents the results of the proposed methodology, investigating an irrigation system that includes a pumping group with five pumps of $160 \mathrm{~kW}$, and finally, the paper ends with a discussion of the results and the concluding remarks.

\section{Irrigation Systems Status in the EU}

In Europe, there is great variability and availability of water resources, hence spatial variability marked in agricultural water management practices and consumption. Climate is the main factor determining water consumption in agriculture, as there are regions where irrigation is the only source of water for growing crops (this is the case in the summer in some Mediterranean areas), while in other regions, irrigation is used as to supplement rain-fed farming. Irrigation technology is also a major factor influencing the level of water consumption in agriculture. The agricultural sector uses $30 \%$ of the total water consumption in Europe but achieves to $70 \%$ of total water consumption in several Southern European countries. In in the countries of the European Union, in 2016, the total irrigable surface was 18.644 million hectares, increasing by $13.4 \%$ compared to 2003 . In 2016, the total irrigated surface was 10.221 million hectares. The biggest share of irrigated surfaces are located in the regions of Mediterranean countries such as Italy, Spain, Cyprus, Greece, Malta and on the coast of Portugal. In Southern European countries, irrigation systems are an important and essential element in major types of agricultural production. In Northern and Central European countries, supplementary irrigation is generally used to improve production in dry summers [31,32]. Figure 1 present the distribution of irrigated areas in EU countries in 2016.

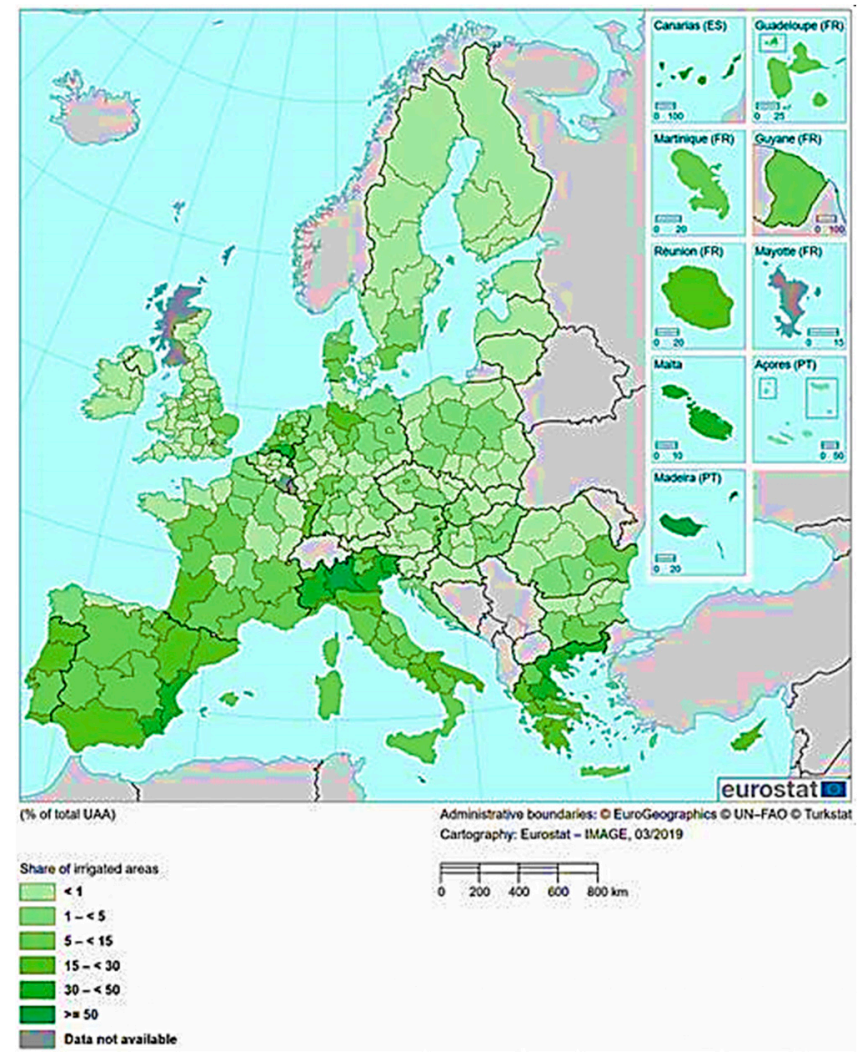

Figure 1. Share of irrigated areas in EU countries in 2016, (Source: Eurostat 2019). 
The biggest share of irrigable surfaces, at country level, are expectedly found in Southern member states: Greece and Malta share $44.9 \%$ and 38.6\%, respectively. Cyprus, Italy and Spain followed with 34.9\%, 33.9\% and 31.1\% respectively. An amazingly high figure was the irrigable surface of the Netherlands, $27.0 \%$, and Denmark, $16.8 \%$, countries less linked to the term of irrigation. In Romania and Slovakia, irrigable surface decreased by $11.2 \%$ and $4.5 \%$ and their share of irrigated areas also decreased by $2.2 \%$ and $3.6 \%$, respectively $[4,33]$.

Taking into consideration that the irrigation systems in Romania were built up during the 1990s, the principal problems now facing the irrigation systems are as follows: low hydraulic efficiency, the high cost of electricity for the systems still based on pumping (the Danube being the main source of water) and high water tariffs. The irrigated area accounts for roughly $22 \%$ of the total agricultural surface of the country and roughly $34 \%$ of the arable area. It is therefore estimated that approximately $11 \%$ of the Romanian agricultural surface is covered by economically viable or marginally viable irrigation networks. Differences occur from one region to another depending on rainfall and irrigation requirements. West, Northwest and Center areas possess less irrigation water, while the Southern and Southeast, areas with water problems, enjoy a greater coverage of irrigation systems, [34].

In Romania, the situation of the current irrigation systems infrastructure is characterized by a low efficiency of base and pumping stations, roughly $45 \%$, and a degree of degradation of waterproofing of canals and hydrotechnical constructions of about $75 \%$. In this sense, Romania, through the National Program for Rehabilitation of the Main Irrigation Infrastructure from 2016, will try to outline the strategic goals required regarding the rehabilitation of the main irrigation infrastructure, leading to an increase in the functional area of the viable surface and an increased economically viable margin for irrigation from $70 \%$ in 2020 to $90 \%$ in 2030 [35]. The specific objective of the program is to increase the efficiency of base (fixed and floating) and pumping stations, eliminating water losses through infiltration from irrigation channels belonging to the public domain and reducing the degradation occurring in hydrotechnical constructions. A solution to increase pumping station efficiency could be the replacement of existing pumps that have a fixed speed $(50 \mathrm{~Hz})$, that are technically outdated, and increasing the variable speed through frequency converters that lead to a significant decrease in energy consumption [36].

\section{Materials and Methods}

In artificial intelligence, an expert system (ES) is a tool capable of emulating the judgment process that a human expert would employ in a decision-making process. The ES was made by extracting knowledge from human experts and was implemented into a computer program for knowledge processing, so that it could handle quantitative and qualitative data. Comparing this system to other conventional programs that require prescript algorithms, the ES allows inexact reasoning and can cope with incomplete data.

Based on its application, the ES can be used in design and planning, control, classification or identification, diagnosis and prediction, etc. A lot of applications were resolved using the ES, such as optimal power allocation between hydropower plants of dispatchable units [37], fault diagnosis in power plants [38,39], power systems control [40], system expansion planning [41,42], power losses evaluation [43], power quality compensators [44] and robotic control domains $[45,46]$.

The authors have chosen the ES for implementing the integrated system to ensure the operation of the pumping group is at safe operating intervals. This system was also used to identify the equivalent pump operating points for the entire flow range and the pumping height of the pumping group, because the specific technique is to follow the behavior of a human expert in the decision-making process. Considering that the ES theory can be applied efficiently to wide areas, their methodology is an ideal approach in irrigation management, as it transfers the new agricultural technologies, developed in the laboratory, directly to the integrated control system that can be embedded in a programmable controller that transmits the control signal to the frequency converter. The 
ES is a dynamic approach that can improve the function of human experts in the decisionmaking process. The following subsections describe the basic structure of the ES and the implementation chosen by the authors for the proposed methodology.

\subsection{The Expert Systems}

The expert systems collect the human decision-making expertise and heuristics representing this information in a series of rules and facts, aiming to solve some difficult problems whose traditional approach would require significant human experience. The knowledge base and inference rules are curated using the experience of the best specialists capable of solving the problems $[47,48]$. Thus, an ES is a computing system that emulates the decision-making ability of the human expert.

The knowledge base contains all the specialized knowledge provided by the human expert's experience and is relevant to a particular field. The knowledge base consists of two parts: the rules basis and the basis of facts. If the rule base is the relatively static part of the knowledge base, the basis of facts is the dynamic part of the knowledge base.

The fundamental issue of the ES is the definition of methods for representing a large amount of knowledge in a form that allows its storage and efficient use. The knowledge representation affects the development, efficiency and speed of the proposed method. Knowledge representation has been realized and developed according to the knowledge specifics, through production rules, semantic frame and object-oriented programming, etc. The production rules are among the most commonly used methods of knowledge representation in the ES and are based on a structure, such as:

$$
\text { Condition (facts) } \Rightarrow \text { Action }
$$

this can be interpreted as follows:

$$
\text { IF (condition is satisfied) } \Rightarrow \text { THEN (action can be performed) }
$$

The knowledge base for the issue, addressed in this paper, totals a series of pumping information groups such as voltages, currents, frequencies, flows for each pump and the pressure that must be constantly maintained throughout the hydraulic operation regime. An example of a production rule associated with the problem of determination the maximum efficiency point in an irrigation system is presented as follows:

IF (requested flow is high) and (pressure is constant) $\Rightarrow$ THEN (maximum efficiency point is recorded in the frequency band)

The inference engine is the logical module of the ES, based on facts it takes the knowledge base rules, builds reasoning, makes associations and links and proposes a solution to the problem. An appropriate calculation method that implements the inference engine is required for the proper processing of all the information in the knowledge base. The basic concept for the ES operation, and its relation to the user, is presented in Figure 2.

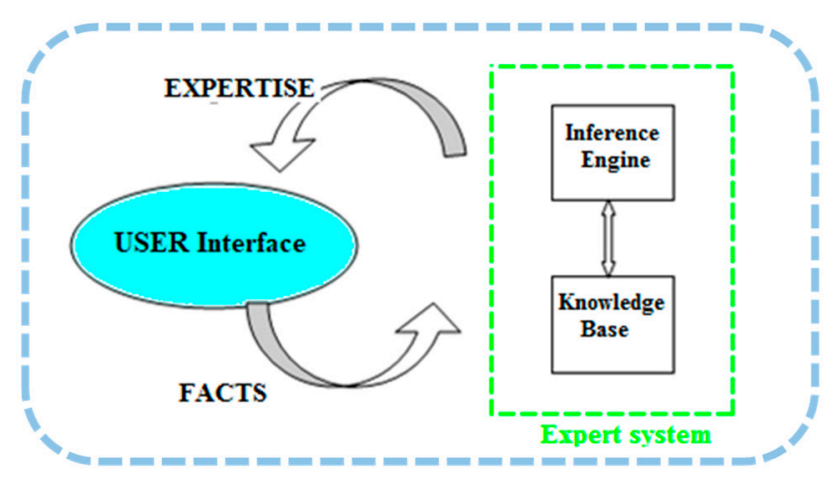

Figure 2. The basic concept of ES operation. 


\subsection{The Proposed Methodology for Irrigation Systems Control}

The problem studied in the paper is based on the principles of an ES and develops a new operating algorithm for the optimization process of energy consumption in pumping groups. Figure 3 presents a flow chart of the integrated system for power consumption optimization and the structure of the integrated system is described in length. Thus, the steps of the proposed methodology, that aims to decrease the energy consumption of a thousand cubic meters pumped, are the following:

1. Introduction of the characteristic parameters for each pump: voltages, currents, frequencies (speeds) and flows for each hydraulic operating mode. First, all Measurements and the organization of the database is necessary. In this step, the data that must be mined is detected, then the appropriate input attributes and output information to represent the task are selected. The characteristic parameters for each pump are identified and organized in the database: voltages, currents, frequencies (speeds) and flows for each hydraulic operating mode. After the first step follows the hydraulic operating regime identification. The analysis was performed on a set of data with several stationary regimes, but without the technological possibility of balancing all possible hydraulic regimes of the pumping station.

2. The input data acquisition and processing, and the calculation of the power consumed for each pump, $i$, where $i$ indicates the pump number from the pumping groups ( $i=1$ $\ldots N_{P}$, where $N_{P}$ represents the total number of pumps from the pumping group) and $n$ represents the number of measurements for a hydraulic operating mode. Thus, the input data subjected to the optimization process have these features recorded in a matrix [ID], having the size $N_{P} \times n$.

$$
[I D]_{N_{P} \times n}=\left[\begin{array}{ccccccccc}
U_{i, 1} & I_{i, 1} & F_{i, 1} & P_{i, 1} & D_{i, 1} & P_{t, 1} & D_{t, 1} & E_{P e, 1} & C_{-} p_{i, 1} \\
U_{i, 2} & I_{i, 2} & F_{i, 2} & P_{i, 2} & D_{i, 2} & P_{t, 2} & D_{t, 2} & E_{P e, 2} & C_{-} p_{i, 2} \\
\ldots & \ldots & & & \ldots \ldots & \ldots & & & \ldots \\
U_{i, n} & I_{i, n} & F_{i, n} & P_{i, n} & D_{i, n} & P_{t, n} & D_{t, n} & E_{P e, n} & C_{-} p_{i, n}
\end{array}\right],
$$

where: $N_{P}$ represents the total number of pumps integrated in the pumping group from the irrigation system; $U_{i, n}$ corresponds to the voltages measured for each pump, $i, i=1 \ldots N_{P}$, in function of the number of measurements for a hydraulic operating mode, $n ; I_{i n}$ indicates the currents measured for each pump, $i, i=1 \ldots N_{P}$, in function of the number of measurements for a hydraulic operating mode, $n ; F_{i, n}$ represents the frequencies (speeds) measured for each pump, $i, i=1 \ldots N_{P}$, in function of the number of measurements for a hydraulic operating mode, $n ; P_{i, n}$ indicates the instantaneous power calculated for each pump, $i, i=1 \ldots N_{P}$, in function of the number of measurements for a hydraulic operating mode, $n ; D_{i, n}$ corresponds to the flows measured for each pump, $i, i=1 \ldots N_{P}$, in function of the number of measurements for a hydraulic operating mode, $n ; P_{t, n}$ represents the power on the equivalent pump in function of $n ; D_{t, n}$ indicates the flow on the equivalent pump in function of $n ; E_{P e, n}$ represents the efficiency of the equivalent pump calculate in function of the number of measurements for a hydraulic operating mode, $n ; C_{\_} p_{i, n}$ corresponds to the pumping cost calculated per 1000 cubic meters pumped per meters in the $\mathrm{H}_{2} \mathrm{O}$ column in function of the number of measurements for a hydraulic operating mode, $n$.

3. Internal step. Frequency band for a hydraulic operating regime. In this step the flow and the power for the equivalent pump, as well as the efficiency of the equivalent pump and the pumping cost, are determined, including all of the parameters in the input data matrix. The following are the detailed parameters calculated in the internal step:

- Count the number of pumps switched on, to calculate the flow on the equivalent pump, $D_{t, n}$;

- Calculate the power of the equivalent pump, $P_{t, n}$; 
- Determine the efficiency of the equivalent pump, $E_{P \mathrm{e}, n}$, using the following relation:

$$
E_{P e, n}=D_{t, n} \cdot H_{s, n} /\left(P_{t} \cdot M_{e} \cdot D f\right),
$$

where: $D_{t, n}$ indicates the total flow in function of the number of measurements for a hydraulic operating mode, $n,\left[\mathrm{~m}^{3} / \mathrm{h}\right] ; H_{s, n}$ represents the pressure of the irrigation system in function of the number of measurements for a hydraulic operating mode, $n$, [bar]; $P_{t}$ corresponds to the total power of the irrigation system, $[\mathrm{kW}] ; M_{e}$ indicates the engine efficiency, given by the catalog, $96 \% ; D_{f}$ represents the motor drive factor (transmission factor) data given by the catalog, [0.9-1].

- Calculate the pumping cost, $C_{-} p_{i, n},\left[\mathrm{~kW} / 1000 \mathrm{~m}^{3} / \mathrm{mcH}_{2} \mathrm{O}\right]$ per 1000 cubic meters pumped per meters in the $\mathrm{H}_{2} \mathrm{O}$ column, in function of the number of measurements for a hydraulic operating mode, $n$, with the relation:

$$
C_{-} p_{i, n}=\left[P_{t} /\left(D_{t, n} / 1000\right)\right] /\left(H_{s, n} * 10\right),
$$

4. Graphical representation of the frequency-flow and frequency-power characteristics for each pump, $F=f\left(D_{i}\right), F=f\left(P_{i}\right)$. The maximum efficiency point is determined from the frequency-flow and frequency-power characteristics analysis. A characteristics representation is made for each pump of a particular hydraulic operating regime.

5. Graphical representation of the frequency-efficiency and frequency-pumping cost for the equivalent pump, $F=f\left(E_{P e, n}\right), F=f\left(C_{-} p_{i, n}\right)$. For a higher accuracy in determining the maximum efficiency point of a pumping group, the frequency-efficiency and frequency-pump cost characteristics for the equivalent pump, of a hydraulic operating regime were determined.

6. Determination of the maximum efficiency point of the hydraulic operating regime. In this last step a decision matrix, which takes into account the pumping cost, the pumping group efficiency and the total flow required at a constant pressure, is developed. From the decision matrix will result the optimal frequency band for which the pumping cost is minimal. The maximum efficiency point is determined for each hydraulic operating regime identified in the second step of the flow chart proposed.

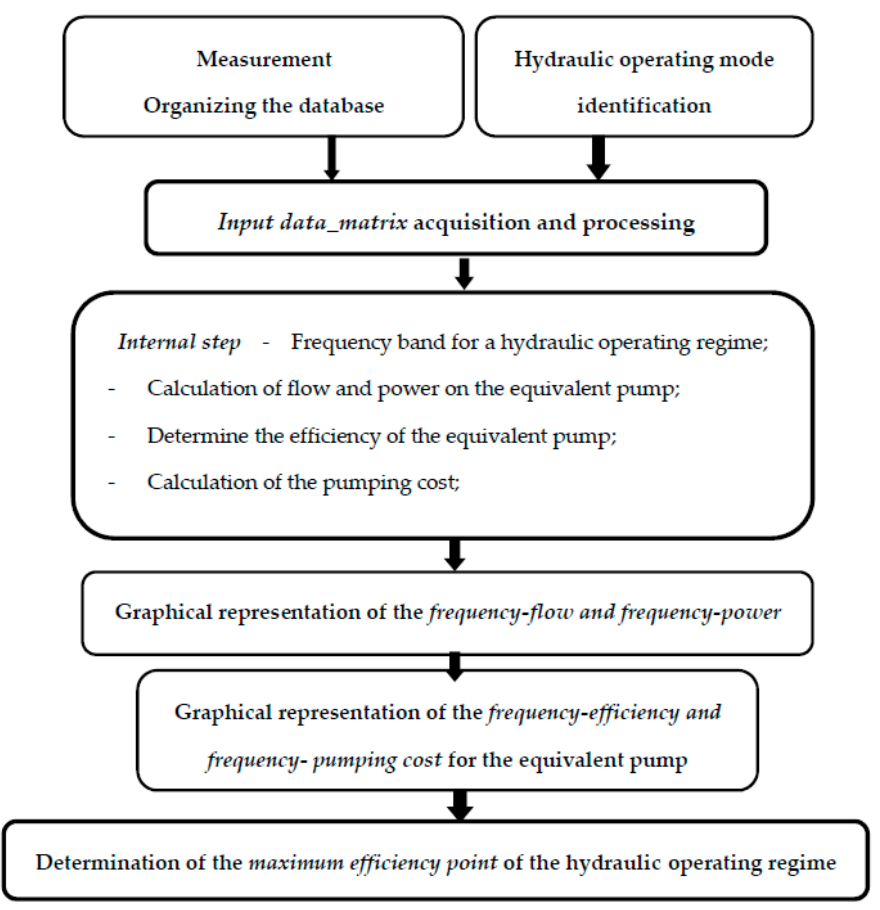

Figure 3. The flow chart of the integrated system for power consumption optimization. 
The developed method is intended to be used for a larger data volume that reflects more hydraulic operating regimes by providing a variable load (variable flow from the pumping station).

\section{Results}

In order to show the characteristics of the proposed methodology an irrigation system from Romania was analyzed, which includes a pumping group with 5 pumps of $160 \mathrm{~kW}$. The technical parameters for the vertical pumps, model (P16C 10554 Y), included in the pumping group, are presented in Tables 2 and 3. The hybrid methodology was developed and implemented in MATLAB.

Table 2. The operating characteristics of the vertical pumps from the pumping group.

\begin{tabular}{cc}
\hline Operating Characteristics of the Vertical Pumps \\
\hline Service flow rate $\left[\mathrm{m}^{3} / \mathrm{h}\right]$ & 504 \\
Service head $[\mathrm{m}]$ & 84 \\
$\mathrm{Q}_{\min }\left[\mathrm{m}^{3} / \mathrm{h}\right]$ & 104.22 \\
$\mathrm{Q}_{\max }\left[\mathrm{m}^{3} / \mathrm{h}\right]$ & 800.07 \\
Hydraulic efficiency [\%] & 82.6 \\
\hline
\end{tabular}

Table 3. The electric motor characteristics for vertical pumps from the pumping group.

\begin{tabular}{ccc}
\hline \multicolumn{1}{c}{ Electric Motor Characteristics } \\
\hline Nominal power [kW] & 160 \\
Rated frequency [Hz] & 50 & \\
Rated current [A] & 277.1 & \\
No. poles $\quad$ Rotation speed & & 1485 \\
[rotations/min] & 4 & 0.87 \\
Power factor & 96.2 \\
\hline
\end{tabular}

The parameters monitored and collected for each vertical pump refers to the voltages, currents, frequencies (speeds) and flows for each hydraulic operating mode. The data measured in the irrigation system was applied to the proposed methodology for different hydraulic operating modes, the cases with two pumps in operation, with three pumps and four pumps. The case with all five pumps in operation was not possible to be analyzed because during the field measurements, the pilot station did not use all pumps. These hydraulic regimes were chosen in this way, because all five vertical pumps are identical.

In the next step, the input data matrix was arranged, and a normalization factor was used because the flow was four measurements/minute and for the voltage, current and frequency were six measurements/minute. It was agreed to mediate in this way so that there was one measurement per minute for all monitored parameters, which means one measurement per minute for $12 \mathrm{~h}$ for a pump in operation, $(60 \times 12=720$ measured values for each parameter per day). In the Figures $4-7$, the normalized monitored parameters for the hydraulic operating mode with four pumps are represented. It is possible to see on the graphs the starting regime of pumps, all monitored parameters recording variations (red circle) until they enter the normal operating regime. 


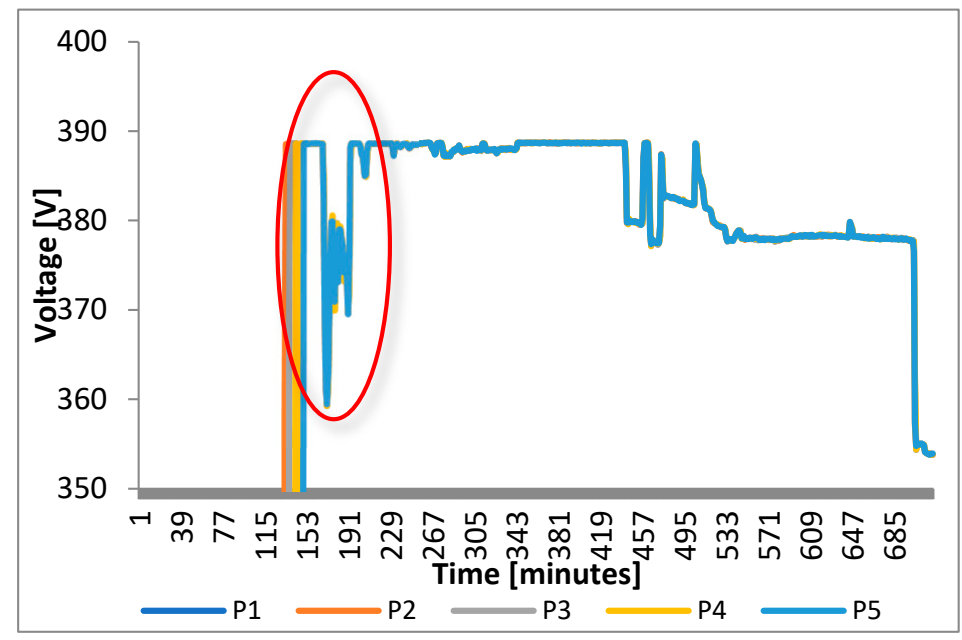

Figure 4. Voltage variations during one day.

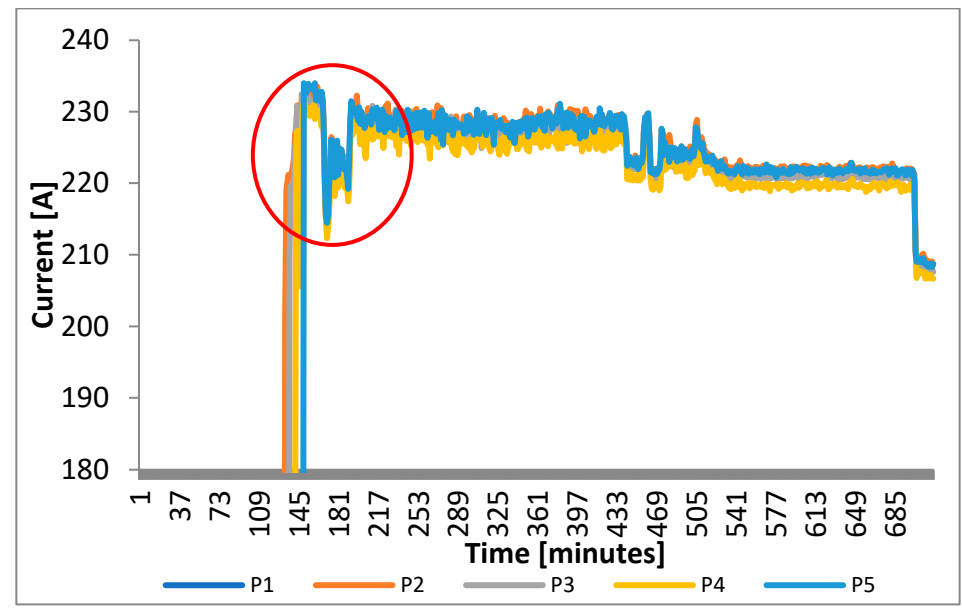

Figure 5. Current values during one day.

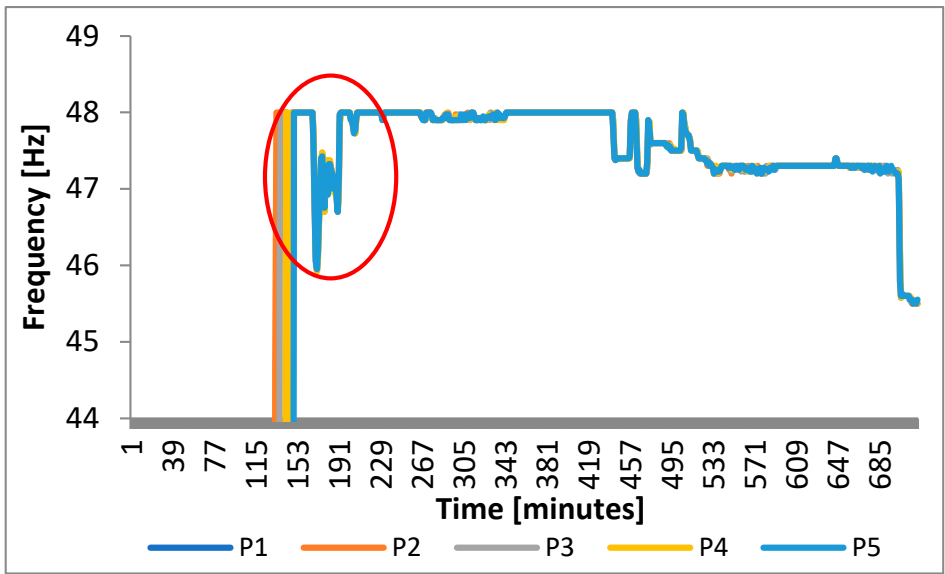

Figure 6. Frequence variations during one day. 


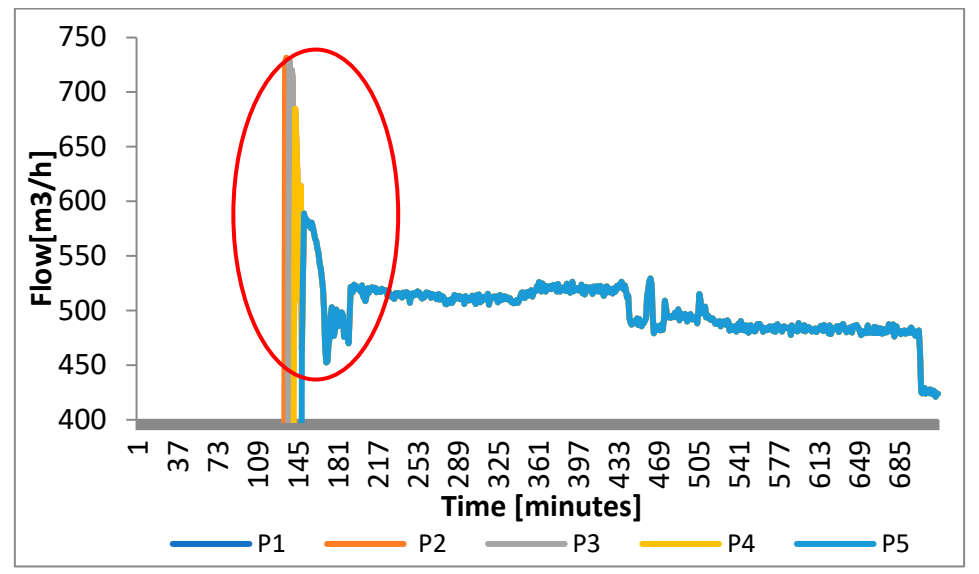

Figure 7. Flow values during one day.

Using the data included in the input data matrix, and the parameter for the equivalent pump, the graphical representation of the characteristics $F=f\left(D_{i}\right), F=f\left(P_{i}\right), F=f\left(E_{P e, n}\right)$, $F=f\left(C_{-} p_{i, n}\right)$, for each hydraulic operating mode, was achieved in the following subsections.

\subsection{Case 1. Hydraulic Operating Mode with 2 Pumps in Operation}

In Figures 8-11 the characteristics $F=f\left(D_{i}\right), F=f\left(P_{i}\right), F=f\left(E_{P e, n}\right)$ and $F=f\left(C_{-} p_{i, n}\right)$ for the case with two pumps in operation are represented. In this case, the pumps in operation are P1 and P2. From the $F=f\left(D_{i}\right)$ and $F=f\left(P_{i}\right)$ characteristics in Figures 8 and 9, two frequency bands of operation can be observed [44-45.5] and [47-48.5], in addition to some sparse values that were excluded in the maximum efficiency point determination. The best degrees of efficiency and the minimal pumping costs are registered in a frequency band [44-45.5], Figures 10 and 11.

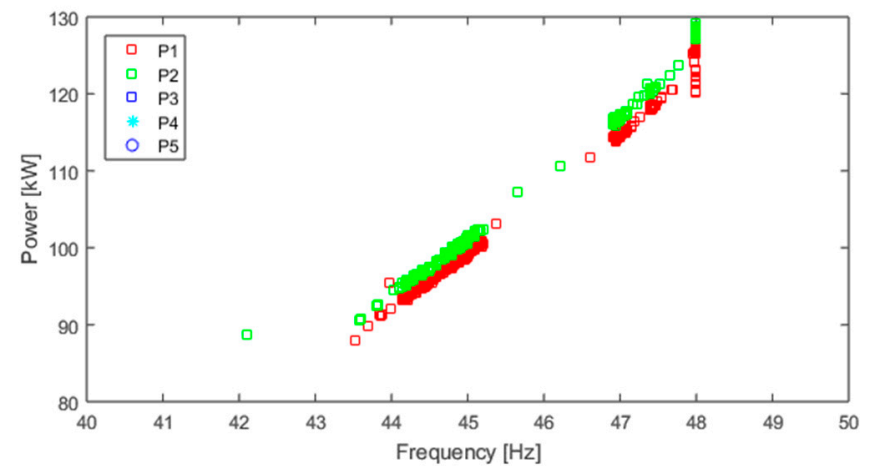

Figure 8. The characteristic $F=f\left(P_{i}\right)$ for the hydraulic regime with two pumps in operation.

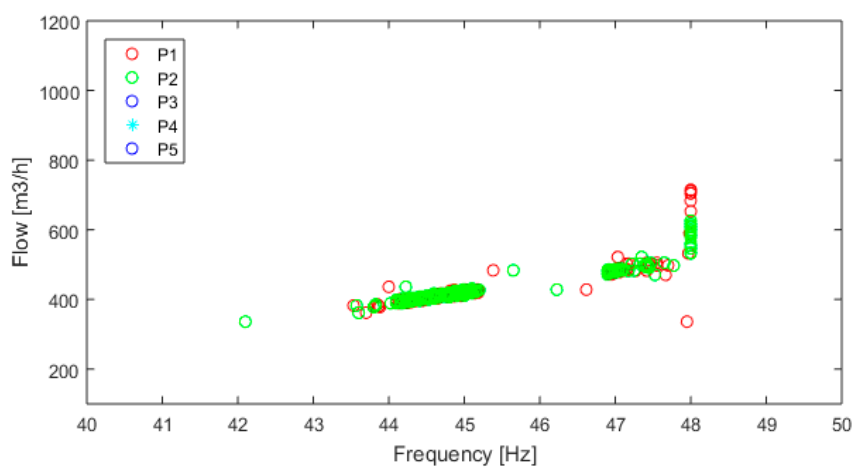

Figure 9. The characteristic $F=f\left(D_{i}\right)$ for the hydraulic regime with two pumps in operation. 


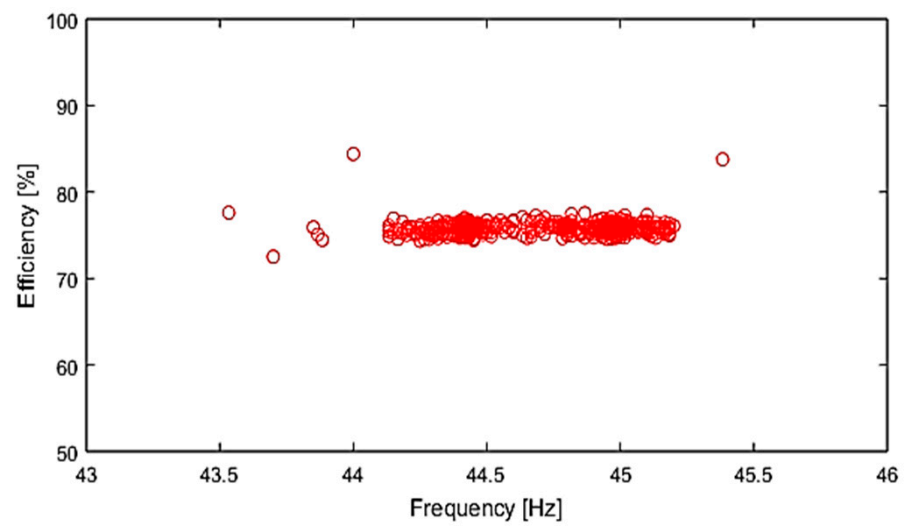

Figure 10. The characteristic $F=f\left(E_{P e, n}\right)$ for the hydraulic regime with two pumps in operation.

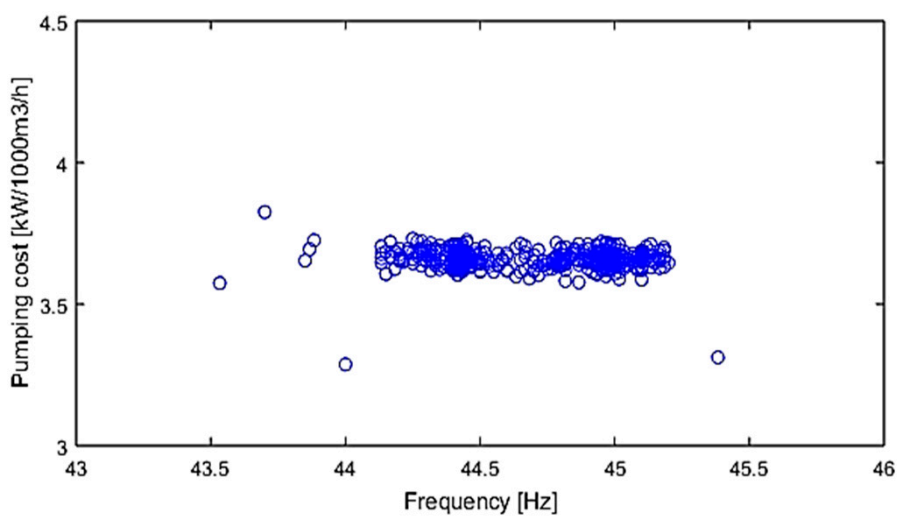

Figure 11. The characteristic $F=f\left(C_{-} p_{i, n}\right)$ for the hydraulic regime with two pumps in operation.

\subsection{Case 2. Hydraulic Operating Mode with 3 Pumps in Operation}

In Figures 12-15, the characteristics $F=f\left(D_{i}\right), F=f\left(P_{i}\right), F=f\left(E_{P e, n}\right)$ and $F=f\left(C_{-} p_{i, n}\right)$ for the case with three pumps in operation are represented. In this case, the pumps in operation are P1, P2 and P4. From the $F=f\left(D_{i}\right)$ and $F=f\left(P_{i}\right)$, characteristics in Figures 12 and 13, a large frequency band of operation can be observed [41.2-47.9], in addition to some sparse values that were excluded in the maximum efficiency point determination. The best degrees of efficiency and the minimal pumping costs are registered in a frequency band [44.5-46.5], Figures 14 and 15.

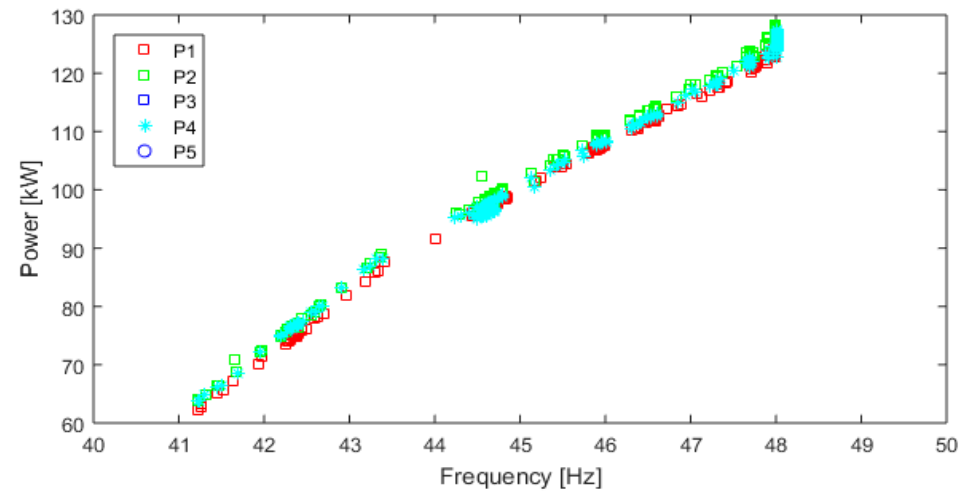

Figure 12. The characteristic $F=f\left(P_{i}\right)$ for the hydraulic regime with three pumps in operation. 


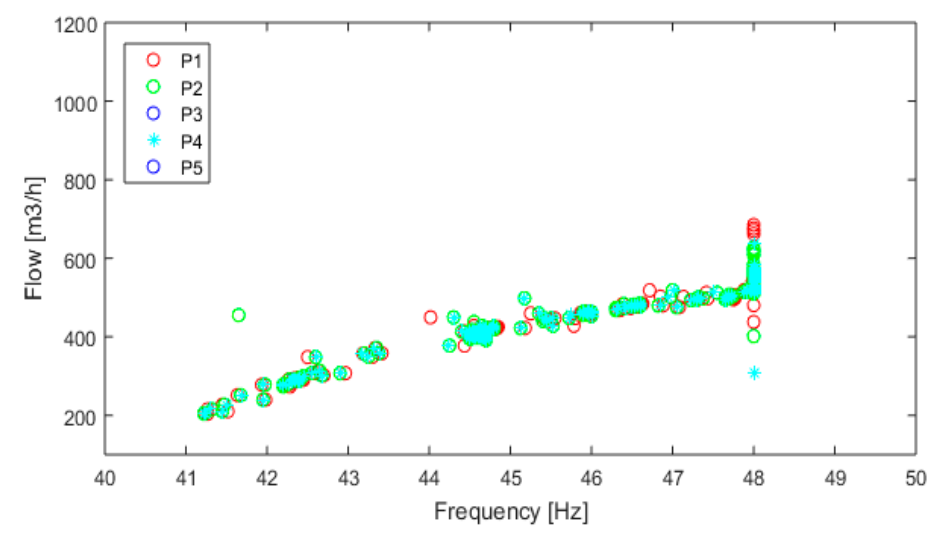

Figure 13. The characteristic $F=f\left(D_{i}\right)$ for the hydraulic regime with three pumps in operation.

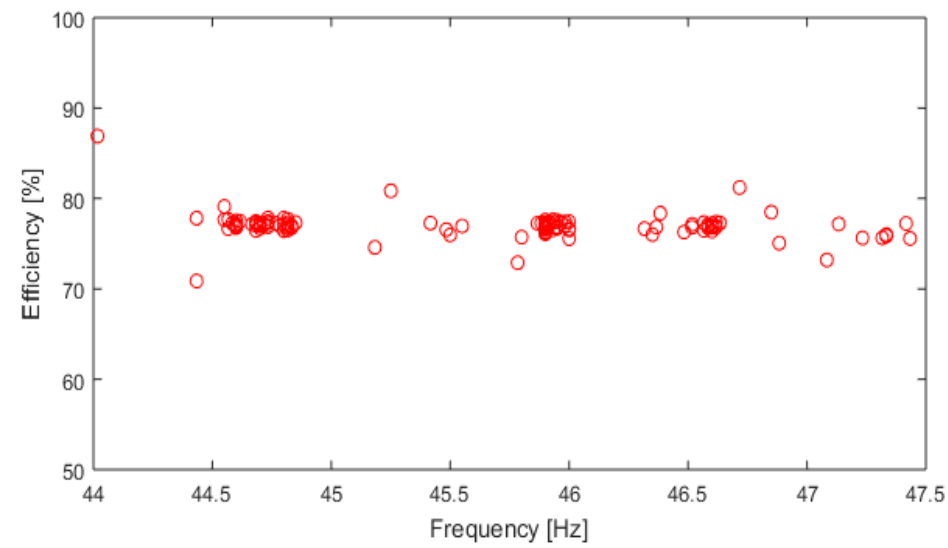

Figure 14. The characteristic $F=f\left(E_{P e, n}\right)$ for the hydraulic regime with three pumps in operation.

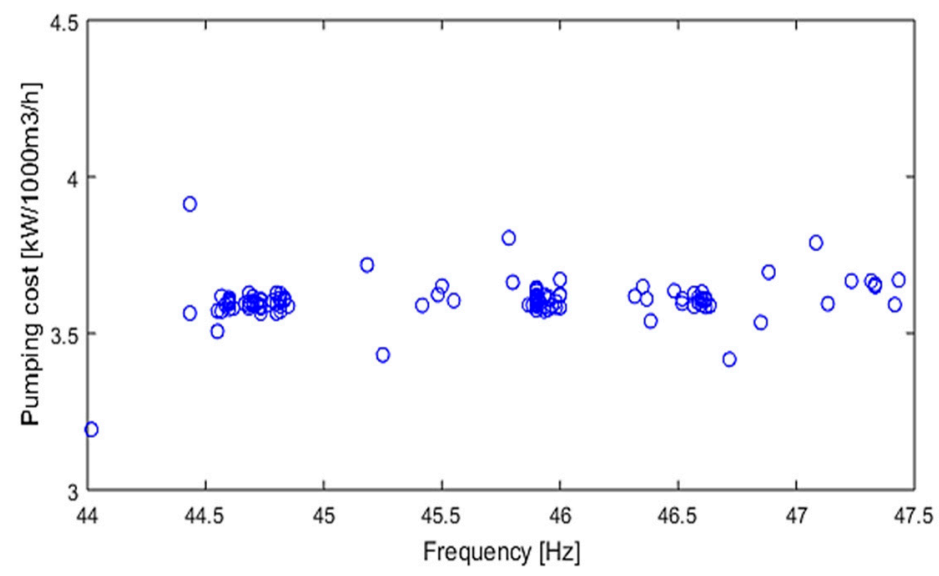

Figure 15. The characteristic $F=f\left(C_{-} p_{i, n}\right)$ for the hydraulic regime with three pumps in operation.

\subsection{Case 3. Hydraulic Operating Mode with 4 Pumps in Operation}

In Figures 16-19, the characteristics $F=f\left(D_{i}\right), F=f\left(P_{i}\right), F=f\left(E_{P e, n}\right)$ and $F=f\left(C_{-} p_{i, n}\right)$, for the case with four pumps in operation, are represented. In this case, the pumps in operation are P1, P2, P3 and P4. From the $F=f\left(D_{i}\right)$ and $F=f\left(P_{i}\right)$ characteristics in Figures 16 and 17, a finite frequency band of operation can be observed [40.7-41.8], in addition to some sparse values that were excluded in the maximum efficiency point determination. The best degrees of efficiency and the minimal pumping costs are registered in a frequency band [41.3-41.8], Figures 18 and 19. 


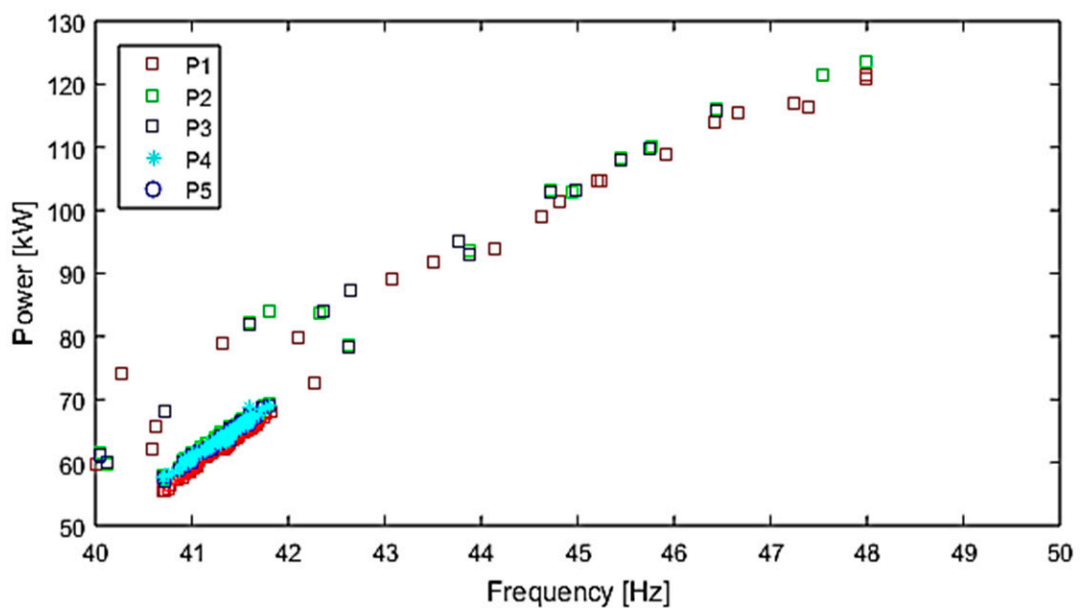

Figure 16. The characteristic $F=f\left(P_{i}\right)$ for the hydraulic regime with four pumps in operation.

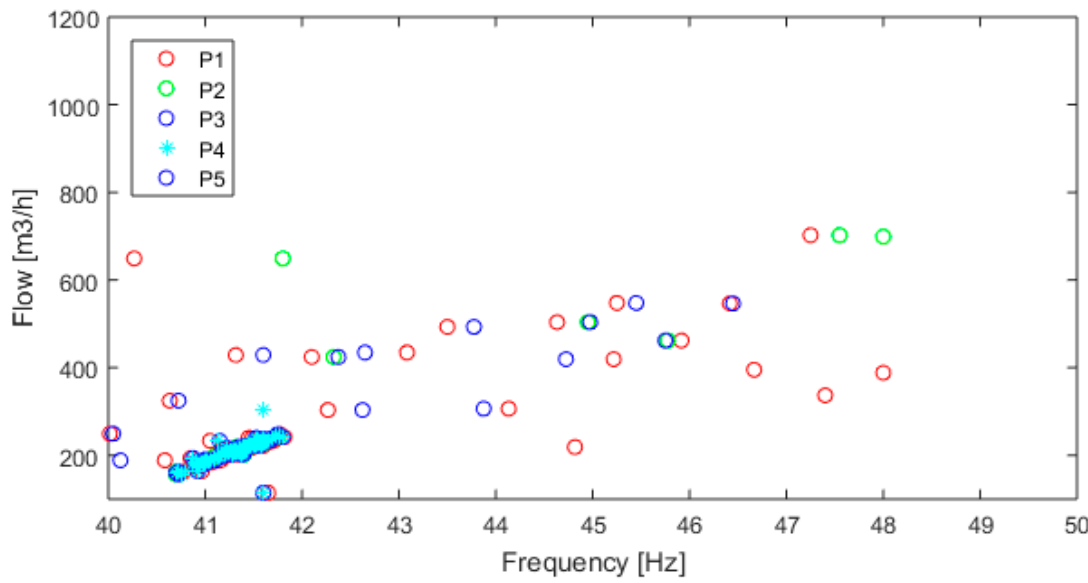

Figure 17. The characteristic $F=f\left(D_{i}\right)$ for the hydraulic regime with four pumps in operation.

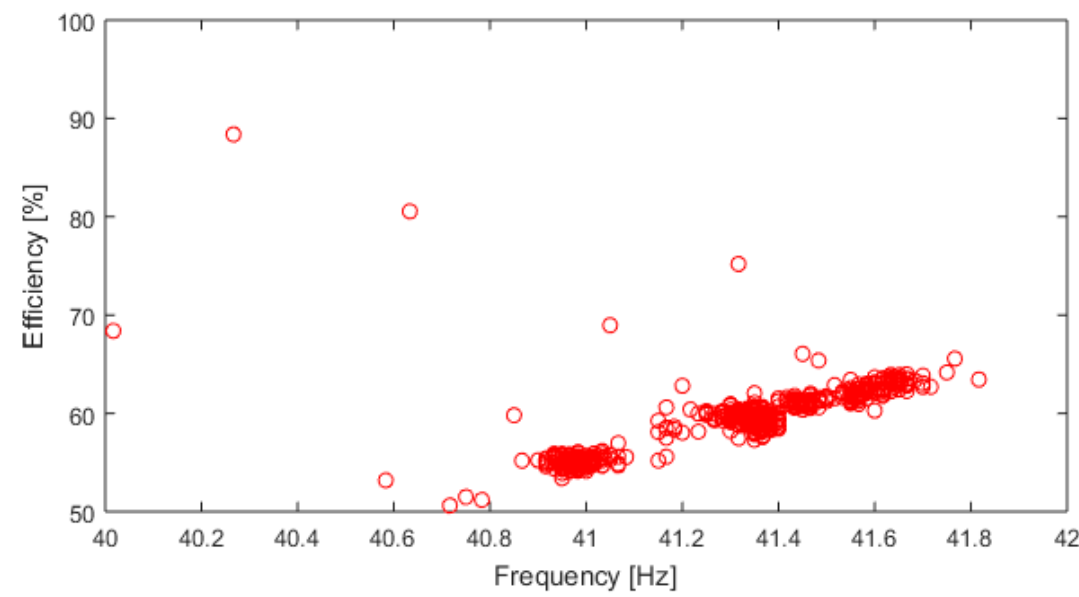

Figure 18. The characteristic $F=f\left(E_{P e, n}\right)$ for the hydraulic regime with four pumps in operation. 


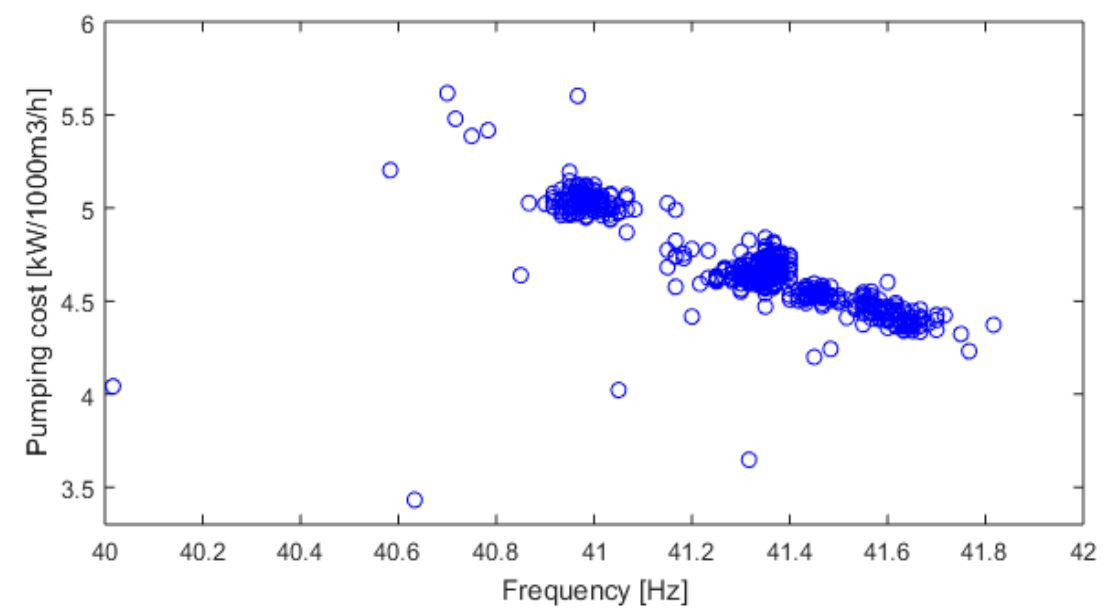

Figure 19. The characteristic $F=f\left(C_{-} p_{i, n}\right)$ for the hydraulic regime with four pumps in operation.

\subsection{The Maximum Efficiency Point Determination Using the Decision Matrix}

In the last step of the hybrid methodology proposed is to develop the decision matrix which takes into account the pumping cost, the pumping group efficiency and the total flow required at a constant pressure. This includes the optimal frequency band result from the graph analysis, when pumping cost is minimal. The maximum efficiency point is determined for each hydraulic operating regime. Thus, the decision matrix, where for the optimal frequency bands are represented the efficiency band, the pumping costs and the flows band for each hydraulic operating regime, is shown in Table 4. Therefore, in Case 1 , with two pumps in operation, the maximum efficiency point recorded in the optimal frequency band is (44-45.5), for Case 2, with three pumps in function, the optimal frequency band is (44.5-46.5) and for Case 3, with four pumps in operation, the maximum efficiency point registered in the optimal frequency band is (41.3-41.8).

Table 4. The decision matrix for each hydraulic operating regime.

\begin{tabular}{|c|c|c|c|c|c|}
\hline \multicolumn{2}{|c|}{ Hydraulic Regime } & $\begin{array}{l}\text { Flow } \\
{\left[\mathrm{m}^{3} / \mathrm{h}\right]}\end{array}$ & $\begin{array}{c}\text { Pumping Cost } \\
{\left[\mathrm{kW} / 1000 \mathrm{~m}^{3} / \mathrm{mcH}_{2} \mathrm{O}\right]}\end{array}$ & $\begin{array}{c}\text { Efficiency } \\
{[\%]}\end{array}$ & $\begin{array}{c}\text { Optimal Frequency Band } \\
{[\mathrm{Hz}]}\end{array}$ \\
\hline Case 1 & $\begin{array}{l}\text { P1 } \\
\text { P2 }\end{array}$ & $(810-850)$ & $(3.64-3.7)$ & $(75.3-76.4)$ & $(44-45.5)$ \\
\hline Case 2 & $\begin{array}{l}\text { P1 } \\
\text { P2 } \\
\text { P4 }\end{array}$ & $(1230-1370)$ & $(3.53-3.60)$ & $(76.7-77.3)$ & (44.5-46.5) \\
\hline Case 3 & $\begin{array}{l}\text { P1 } \\
\text { P2 } \\
\text { P3 } \\
\text { P4 }\end{array}$ & (890-930) & $(4.24-4.5)$ & $(61.5-65.3)$ & $(41.3-41.8)$ \\
\hline
\end{tabular}

\section{Discussion}

In this paper, an integrated system for optimizing the energy consumption for $1000 \mathrm{cu}-$ bic meters pumped in a pumping group within an irrigation system, was developed. The proposed methodology, based on the principles of expert systems, has been successfully used to establish the maximum efficiency point for each hydraulic operating regime. Sensitivity information was embedded in the procedure through the determination of the optimal frequency band for which the pumping cost is minimal. The results have been compared to those obtained in the case of the algorithms having incorporated machine-learning techniques, as well as the optimization methods, to address real-life and large-sized water distribution systems [12]. The codes of the algorithms have been written in programming language MATLAB 2016, and it has been run on a computer with the following characteris- 
tics: Intel Core i7 processor, $2.0 \mathrm{GHz}, 8 \mathrm{~GB}$ RAM memory and a Windows 10 64-bit operating system. The proposed hybrid methodology obtained the solution process relatively fast (10 s), excluding cases which violated system constraints under any operating conditions while during [12] the $20 \mathrm{~s}$. However, it is difficult to appreciate the efficiency of a method, due to the differences between computational technologies used. Using the proposed methodology, with the easy implementation of the ES principles for unsupervised learning in the decision-making process, the computation time and the volume calculation were reduced significantly by exploiting the knowledge of the characteristic parameters for each pump from the pumping group.

Based on the decision matrix results obtained from the integrated system, the human operator can modify the program from the PLC and can implement the decision matrix with a granularity that will take into account the PLC capabilities. Depending on the hydraulic regime and decision matrix, the optimum operating mode was proposed on the automation system screen (HMI, PC etc. ... ) through clear messages addressed to the human operator, which will consist of number of pumps that should work for a minimum consumption of one thousand cubic meters pumped. After raising the level of confidence in the expert system implemented in PLC, it will be possible to move towards the automatic switching of the operating mode. The numerical results obtained for each hydraulic operating regime in the pumping group indicated that the proposed methodology is effective in achieving the minimum energy consumption.

\section{Conclusions}

The paper takes a new approach concerning the smart management of energy consumption in irrigation systems. In comparison to the approach in which the irrigation system is oriented to the controller's design that can support the levels required in the irrigation canals thereby satisfying the water irrigation demand, the methodology proposed by the authors considered optimally scheduling the pumping groups in order to reduce energy consumption. Using the flexibility of the ES principles, the three cases were modeled, making the results easier to compare and evaluate, a feature that is a key factor for the optimal management of irrigation systems and for the determination of a maximum efficiency point in each hydraulic operating regime. Based on the numerical results achieved for each hydraulic operating regime, the decision matrix can efficiently identify the optimal frequency band in function of minimal pumping cost. It is expected that the impact of these integrated systems on power consumption optimization in pumping groups will provide even more insight regarding the optimal management of irrigation systems.

Author Contributions: Conceptualization, F.S., G.G. and V.-A.S.; methodology, F.S.; software, F.S. and O.I.; validation, F.S., G.G. and V.-A.S.; formal analysis, G.G.; investigation, F.S.; resources, V.-A.S., B.-C.N. and O.I.; data curation, F.S. and B.-C.N.; writing-original draft preparation, F.S.; writingreview and editing, F.S., G.G. and B.-C.N. All authors have read and agreed to the published version of the manuscript.

Funding: This research received no external funding.

Conflicts of Interest: The authors declare no conflict of interest.

\section{References}

1. Improving Pivot Irrigation Systems with Automation Direct. Available online: https://library.automationdirect.com/improving -pivot-irrigation-systems-with-automationdirect-issue-37-2017/ (accessed on 28 September 2021).

2. Nikolaou, G.; Neocleous, D.; Katsoulas, N.; Kittas, C. Irrgation of Greenhouse Crops. J. Hortic. 2019, 5, 7. [CrossRef]

3. Sowah, R.A.; Armoo, S.K.; Koumadi, K.M.; Agyeman, R.; Fiawoo, S.Y. Design and Development of an Efficient and Cost-Effective Microcontroller-Based Irrigation Control System to Enhance Food Security. Int. J. Electr. Inf. Eng. 2014, 8, 1343-1350.

4. Agri-Environmental Indicator-Irrigation. Available online: http://ec.europa.eu/eurostat/statistics-explained/index.php/Agrienvironmental_indicator_-_irrigation (accessed on 12 September 2021).

5. Farm Level Optimal Water Management Assistant for Irrigation under Deficit. Available online: https://www.wur.nl/upload_ mm/3/9/0/ba6fb1fe-5281-4f64-b4f9-1ce9dbd1c61f_FlowAid_Brochure.pdf (accessed on 3 September 2021). 
6. Environment Action Programme to 2030. Available online: https://ec.europa.eu/environment/strategy/environment-action-p rogramme-2030_en\#: \{\}:text=These \%20include\%20biodiversity $\% 201$ oss $\% 2 \mathrm{C} \% 20$ climate $\% 20$ change $\% 2 \mathrm{C} \% 20$ resource $\% 20$ use,cli mate\%20action\%20objectives\%20of\%20the\%20European\%20Green\%20Deal (accessed on 15 September 2021).

7. Automatic Watering System. Available online: http://www.novedades-agricolas.com/en/irrigation/irrigation-systems/autho matic-watering-system (accessed on 1 September 2021).

8. Levidow, L.; Zaccaria, D.; Maia, R.; Vivas, E.; Todorovic, M.; Scardigno, A. Improving water-efficient irrigation: Prospects and difficulties of innovative practices. Agric. Water Manag. 2014, 146, 84-94. [CrossRef]

9. Benzaouia, M.; Hajji, B.; Anne, M.-D.; Mellit, A.; Abdelhamid, R. An intelligent irrigation system based on fuzzy logic control: A case study for Moroccan oriental climate region. In Proceedings of the 2nd International Conference on Embedded Systems and Artificial Intelligence (ESAI'21), Fez, Morocco, 1-2 April 2021.

10. Jamroen, C.; Komkum, P.; Fongkerd, C.; Krongpha, W. An Intelligent Irrigation Scheduling System Using Low-Cost Wireless Sensor Network toward Sustainable and Precision Agriculture. IEEE Access 2020, 8, 172756-172769. [CrossRef]

11. Puy, A.; Borgonovo, E.; Lo Piano, S. Irrigated areas drive irrigation water withdrawals. Nat. Commun. 2021, 12, 4525. [CrossRef]

12. Bagloee, S.A.; Asadi, M.; Patriksson, M. Minimization of water pumps' electricity usage: A hybrid approach of regression models with optimization. Expert Syst. Appl. 2018, 107, 222-242. [CrossRef]

13. Difallah, W.; Benahmed, K.; Draoui, B.; Bounaama, F. Linear Optimization Model for Efficient Use of Irrigation Water. Int. J. Agron. 2017, 2017, 5353648. [CrossRef]

14. Singh, A.; Panda, S.N. Optimization and Simulation Modelling for Managing the Problems of Water Resources. Water Resour. Manag. 2013, 27, 3421-3431. [CrossRef]

15. Azimi, V.; Salmasi, F.; Entekhabi, N.; Tabari, H.; Niaghi, A.R. Optimization of Deficit Irrigation Using Non-Linear Programming, (Case study:Mianeh region, Iran). Int. J. Agric. Crop. Sci. 2013, 6, 252-260.

16. Bockari-Gevao, S.M.; Wan Ishak, W.I.; Azmi, Y.; Chan, C.W. Analysis of energy consumption in lowland rice-based cropping system of Malaysia. Songklanakarin J. Sci. Technol. 2005, 27, 819-826.

17. Jiang, L.; Songa, J.; Li, M.; Shang, S.; Ma, X.; Yang, J.; Adeloyed, A. Optimization of irrigation scheduling for spring wheat based on simulation-optimization model under uncertainty. Agric. Water Manag. 2018, 208, 245-260.

18. Galindo, J.; Torok, S.; Salguero, F.; De Campos, S.; Romera, J.; Puig, V. Optimal Management of Water and Energy in Irrigation Systems: Application to the Bardenas Canal. IFAC-PapersOnLine 2017, 50, 6613-6618. [CrossRef]

19. Fang, Z.X.; Voron, B.; Bocquillon, C. Dynamic Programming: A Model for an Irrigation Reservoir. Hydrol. Sci. J. 1989, 34, 415-424. [CrossRef]

20. Zhang, D.; Guo, P.; Liu, X.; Chen, J.; Jiang, C. Greenhouse Irrigation Optimization Decision Support System. In Proceedings of the 7th International Conference on Computer and Computing Technologies in Agriculture (CCTA), Beijing, China, 18-20 September 2013; Springer: Berlin/Heidelberg, Germany, 2014; pp. 10-23.

21. Kuo, S.F.; Liu, C.W. Simulation and Optimization Model for Irrigation Planning and Management. Hydrol. Process. 2003, 17, 3141-3159. [CrossRef]

22. De Ocampo, A.L.P.; Dadios, E.P. Energy Cost Optimization in Irrigation System of Smart Farm by Using Genetic Algorithm. In Proceedings of the IEEE 9th International Conference on Humanoid, Nanotechnology, Information Technology, Communication and Control, Environment and Management, Manila, Philippines, 1-3 December 2017. [CrossRef]

23. Moradi-Jalal, M.; Rodin, S.I.; Marino, M.A. Use of Genetic Algorithm in Optimization of Irrigation Pumping Stations. J. Irrig. Drain. Eng. 2004, 130, 357-365. [CrossRef]

24. Gao, L.; Zhang, M.; Chen, G. An intelligent irrigation system based on wireless sensor network and fuzzy control. J. Netw. 2013, 8, 1080-1087. [CrossRef]

25. Mohapatraa, A.G.; Lenka, S.K. Neural Network Pattern Classification and Weather Dependent Fuzzy Logic Model for Irrigation Control in WSN Based Precision Agriculture. Procedia Comput. Sci. 2016, 78, 499-506. [CrossRef]

26. Marinescu, T.; Arghira, N.; Hossu, D.; Fagarasan, I.; Stamatescu, I.; Stamatescu, G.; Calofir, V.; Iliescu, S. Advanced control strategies for irrigation systems. In Proceedings of the 9th IEEE International Conference on Intelligent Data Acquisition and Advanced Computing Systems: Technology and Applications, Bucharest, Romania, 21-23 September 2017. [CrossRef]

27. Capraro, F.; Patino, D.; Tosetti, S.; Schugurensky, C. Neural Network-Based Irrigation Control for Precision Agriculture. In Proceedings of the IEEE International Conference on Networking, Sensing and Control, Sanya, China, 6-8 April 2008. [CrossRef]

28. Srinivasan, R.; Engel, B.A.; Paudyal, G.N. Expert System for Irrigation Management. Agric. Syst. 1991, 36, 297-314. [CrossRef]

29. Mohan, S.; Arumugam, N. Expert System Applications in Irrigation Management: An Overview. Comput. Electron. Agric. 1997, 17, 263-280. [CrossRef]

30. Adeyemi, O.; Grove, I.; Peets, S.; Norton, T. Advanced Monitoring and Management Systems for Improving Sustainability in Precision Irrigation. Sustainability 2017, 9, 353. [CrossRef]

31. Giannakis, E.; Bruggeman, A.; Djuma, H.; Kozyra, J.; Hammer, J. Water pricing and irrigation across Europe: Opportunities and constraints for adopting irrigation scheduling decision support systems. Water Sci. Technol. Water Supply 2016, 16, 245-252. [CrossRef]

32. Wastewater. The Untapped Resource, The United Nations World Water Development Report. 2017. Available online: http: / / unesdoc.unesco.org/images/0024/002475/247553e.pdf (accessed on 28 August 2021). 
33. Intrigliolo, D. Water and Energy Advanced Management for Irrigation. The Future of Smart Irrigation Management in Europe, WEAM4i Policy Brief. 2014. Available online: www.weam4i.eu (accessed on 10 September 2021).

34. Năstase, G.; Şerban, A.; Năstase, A.F.; Dragomir, G.; Brezeanu, A.I.; Iordan, N.F. Hydropower development in Romania. A review from its beginnings to the present. Renew. Sustain. Energy Rev. 2017, 80, 297-312. [CrossRef]

35. National Program for Rehabilitation of the Main Irrigation Infrastructure in Romania. 2016. Available online: http://www.madr .ro/docs/agricultura/programul-national-reabilitare-irigatii-update.pdf (accessed on 9 September 2021).

36. Agriculture in Romania 2017, Flanders Investment \& Trade Market Survey. Available online: https:/ /www.flandersinvestmenta ndtrade.com/export/sites/trade/files/market_studies/2017_Agriculture_Romania.pdf (accessed on 5 September 2021).

37. Grigoras, G.; Scarlatache, F.; Comanescu, D.; Bogdan, C. Expert System for Optimal Power Allocation in Hydropower Dispatchable Units. In Proceedings of the International Conference OPTIM-ACEMP 2017 on Optimization of Electrical \& Electronic Equipment-Aegean Conference on Electrical Machines and Power Electronics, Brasov, Romania, 25-27 May 2017 ; pp. 605-610.

38. Mayadevi, N.; Vinodchandra, S.S.; Ushakumari, S. A Review on Expert System Applications in Power Plants. Int. J. Electr. Comput. Eng. (IJECE) 2014, 4, 116-126.

39. Faisal, M.; Mohamed, A.; Shareef, H.; Hussain, A. Power Quality Diagnosis Using Time Frequency Analysis and Rule Based Techniques. Expert Syst. Appl. 2011, 38, 12592-12598. [CrossRef]

40. Niebur, D. Expert Systems for Power System Control in Western Europe. In Proceedings of the 5th IEEE Int. Symposium on Intelligent Control, Philadelphia, PA, USA, 5-7 September 1990; pp. 34-40. [CrossRef]

41. Gajbhiye, R.K.; Naik, D.; Dambhare, S.; Soman, S.A. An Expert System Approach for Multi-Year Short-Term Transmission System Expansion Planning: An Indian Experience. IEEE Trans. Power Syst. 2008, 23, 226-237. [CrossRef]

42. HeungJae Lee, L.; ChaNyeon, K.; WonKun, Y. Application of an Expert System for Planning of Primary Restorative System. Int. J. Appl. Innov. Eng. Manag. (IJAIEM) 2016, 5, 301-305.

43. León, C.; Biscarri, F.; Monedero, I.; Guerrero, J.I.; Biscarri, J.; Millán, R. Integrated expert system applied to the analysis of non-technical losses in power utilities. Expert Syst. Appl. 2011, 38, 10274-10285. [CrossRef]

44. Liberado, E.V.; Marafão, F.P.; Simões, M.G.; De Souza, W.A.; Pomilio, J.A. Novel expert system for defining power quality compensators. Expert Syst. Appl. 2015, 42, 3562-3570. [CrossRef]

45. Gua, J.S.; De Silva, C.W. Development and Implementation of a Real-Time Open-Architecture Control System for Industrial Robot Systems. Eng. Appl. Artif. Intell. 2004, 17, 469-483. [CrossRef]

46. Devedžić, V. REX: Robotics expert systems building tool. Eng. Appl. Artif. Intell. 1989, 2, 286-299. [CrossRef]

47. Cârţină, G.; Grigoraş, G. Artificial Intelligence Techniques in Electroenergetics; House Publishing SETIS: Iasi, Romania, 2004.

48. Garbea, R.; Scarlatache, F.; Grigoras, G.; Neagu, B. Integration of Data Mining Techniques in SCADA System for Optimal Operation of Hydropower Plants. In Proceedings of the 2021 13th International Conference on Electronics, Computers and Artificial Intelligence (ECAI), Pitesti, Romania, 1-3 July 2021; pp. 1-6. [CrossRef] 